\title{
Diurnal surface fuel moisture prediction model for Calabrian pine stands in Turkey
}

\author{
Ertugrul Bilgili ${ }^{(1)}$, \\ Kadir Alperen Coskuner ${ }^{(1)}$, \\ Yetkin Usta ${ }^{(1)}$, \\ Bulent Saglam ${ }^{(2)}$, \\ Omer Kucuk ${ }^{(3)}$, \\ Tolga Berber ${ }^{(4)}$, \\ Merih Goltas ${ }^{(5)}$
}

\begin{abstract}
This study presents a dynamic model for the prediction of diurnal changes in the moisture content of dead surface fuels in normally stocked Calabrian pine stands under varying weather conditions. The model was developed based on several empirical relationships between moisture contents of dead surface fuels and weather variables, and calibrated using field data collected from three Calabrian stands from three different regions of Turkey (Mugla, southwest; Antalya, south; Trabzon, north-east). The model was tested and validated with independent measurements of fuel moisture from two sets of field observations made during dry and rainy periods. Model predictions showed a mean absolute error (MAE) of $1.19 \%$ for litter and $0.90 \%$ for duff at Mugla, and $3.62 \%$ for litter and $14.38 \%$ for duff at Antalya. When two rainy periods were excluded from the analysis at Antalya site, the MAE decreased from $14.38 \%$ to 4.29\% and $\mathrm{R}^{2}$ increased from 0.25 to 0.83 for duff fuels. Graphical inspection and statistical validation of the model indicated that the diurnal litter and duff moisture dynamics could be predicted reasonably. The model can easily be adapted for other similar fuel types in the Mediterranean region.
\end{abstract}

Keywords: Fuel Moisture Content, Modeling, Drying Rate, Vapor Pressure Deficit measurements. However, empirical models are static in nature and may be reliable only within the constraints of a particular data set, or for circumstances that are similar to those where the data were gathered (Sievanen et al. 1988). Process-based models are designed to predict fuel moisture contents from the simulation of processes occurring in the fuels based on physics ( $\mathrm{Nel}-$ son 2000, Matthews 2006), or empirical fundamentals or both (Rothermel et al. 1986, Van Wagner 1987). Such a modeling approach requires theoretical understanding of the processes involved and their parameter values (Matthews 2014). Additionally, they are usually complex and require many parameters that are not practically measured in the field (Jose et al. 2013).

Regression and process-based models may, on their own right, provide very suc-
(1) Karadeniz Technical University, Faculty of Forestry, 61080 Trabzon (Turkey); (2) Artvin Coruh University, Faculty of Forestry, 08000 Artvin (Turkey); (3) Kastamonu University, Faculty of Forestry, 37200 Kastamonu (Turkey); (4) Karadeniz Technical University, Faculty of Science, 61080 Trabzon (Turkey); (5) Istanbul University, Faculty of Forestry, 34100 Istanbul (Turkey)

@ Yetkin Usta (yetkinusta@ktu.edu.tr)

Received: May 29, 2018 - Accepted: Feb 27, 2019

Citation: Bilgili E, Coskuner KA, Usta Y, Saglam B, Kucuk O, Berber T, Goltas M (2019). Diurnal surface fuel moisture prediction model for Calabrian pine stands in Turkey. iForest 12: 262 -

271. - doi: 10.3832/ifor2870-012 [online 2019-05-03]

Communicated by: Davide Ascoli cessful results. However, limitations and complexities of existing models limit their use under different conditions. The power of statistical and physical models may be increased by combining empirical and theoretical modeling approaches (Sievanen et al. 1988). Here an attempt was made to construct a state-dependent dynamic model using empirical relationships that are structured in such a way as to mimic most important fuel moisture dynamics processes such as desorption and adsorption, thereby maintaining an acceptable level of functional realism as opposed to precision or generality. The proposed model simulates diurnal changes in the moisture content of surface fuels based on the difference between concurrent fuel moisture and equilibrium moisture content (EMC), regulated by Timelag. EMC and Timelag are intermediate variables used to predict fuel moisture contents in the model. EMC is the fuel moisture content attainable under constant temperature and relative humidity conditions (Blackmarr 1971). Timelag, varying in relation to environmental conditions, determines moisture response characteristics of dead surface fuels between concurrent fuel moisture and EMC (Byram 1963).

In the proposed model, environmental conditions determine the surface fuel moisture content, and moisture dynamics are considered to depend mostly on weather variables such as relative humidity, air temperature, wind speed and precipitation ( $\mathrm{Si}$ mard 1968, Van Wagner 1979). Surface fuels increase their moisture from condensa- 
tion, precipitation and through the adsorption of water vapor (Viney \& Hatton 1990). Soil moisture is also known to affect duff and surface litter moisture (Wittich 2005). However, soil moisture effect was not accounted for in this study. Dead fuels lose their moisture by evaporation and desorption (Gonzalez et al. 2009). Adsorption and desorption are complementary processes governed by relative humidity, air temperature and the rate of diffusion of moisture through the fuel (Nelson 1984). Wind and solar heating are other weather factors driving fuel moisture dynamics (Rothermel et al. 1986).

The objective of this study is to develop a dynamic model to predict surface fuel moisture dynamics on an hourly basis during dry and rainy periods in a "standard fuel type" characterized by fully grown, normally stocked Calabrian pine (Pinus brutia L.) stands. Calabrian pine has a wide distribution in the eastern Mediterranean region and is the most common tree species in Turkey, covering a land area of 5.85 million ha (the largest area worldwide - GDF 2015). Pure natural stands of Calabrian pine are mostly found in fire prone areas in Turkey and usually originate from high-intensity, stand-replacing fires (Turna \& Bilgili 2006). Most fires occur in pure or mixed Calabrian pine stands, often leading to the loss of goods, services, resources and even lives in Turkey (Tavsanoglu \& Gürkan 2009).

Many efforts have been made to predict moisture content of surface fuels in Pinus stands (Van Wagner 1977, Anderson et al. 1978, Pook 1993, Tanskanen et al. 2006, Schunk et al. 2013) including Mediterranean sites (Saglam et al. 2006, Gonzalez et al. 2009, Lopes et al. 2014a, Bilgili et al. 2018). However, predictions of the models for comparable weather conditions may differ significantly due to differences in fuel characteristics for different species (Pook 1993) and locations. Moreover, only two studies involved Calabrian pine stands
Fig. 1 - Flowchart of the model.

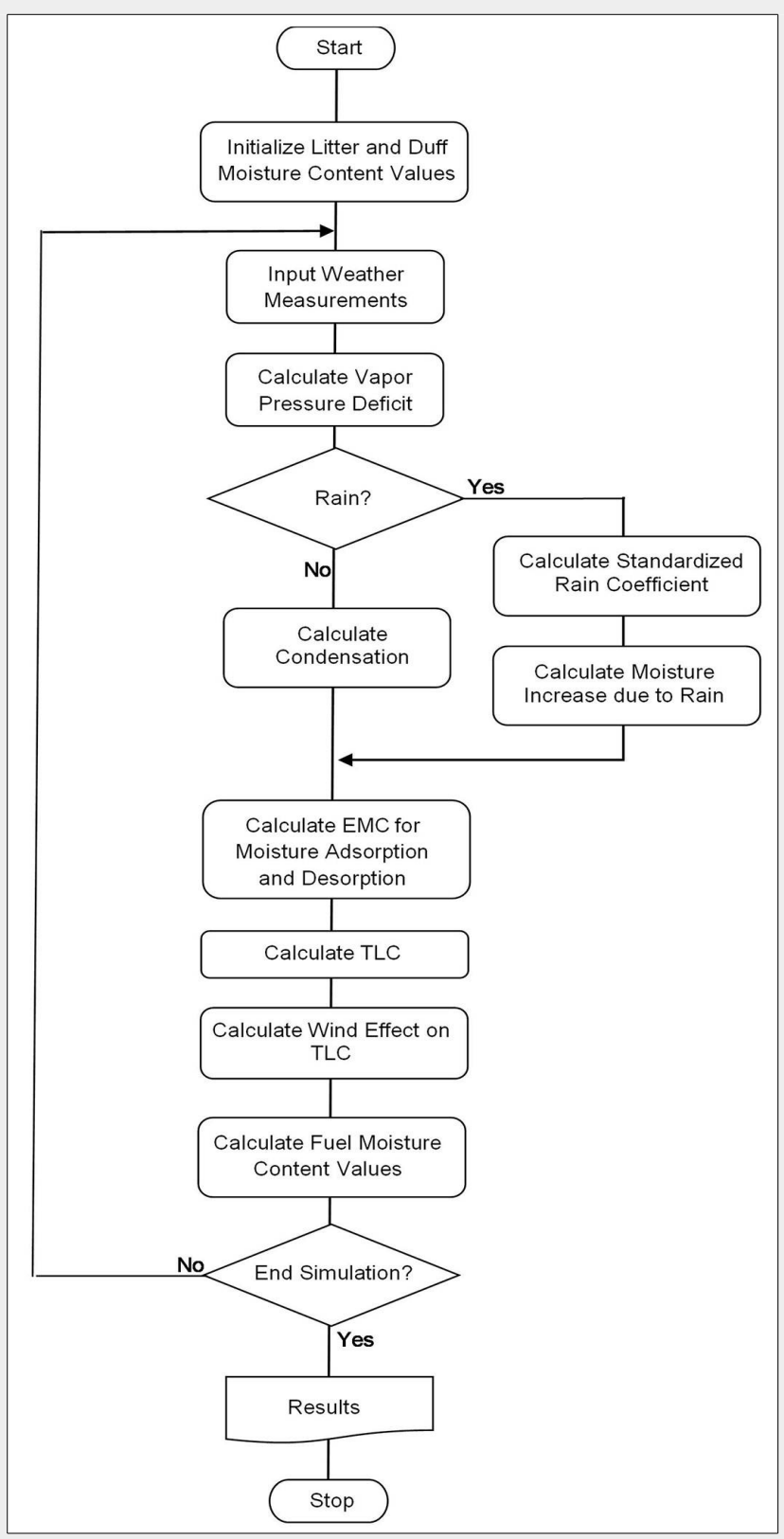

so far (Saglam et al. 2006, Bilgili et al. 2018); the first study produced daily predictions only, with no provisions for diurnal changes in surface fuel moistures, while the latter provided diurnal predictions, but for precipitation-free periods only.

\section{Material and methods}

\section{Model overview}

A state-dependent model of surface fuel moisture dynamics was developed. The model can be considered a blend of empirical and process-based models. In that, it utilizes empirical relationships to quantitatively describe functional relationships that are common to a wide range of situations rather than fitting limited moisture responses from a set of measured situations. The model is based on the rate of change of fuel moisture contents depending on the difference between the concurrent fuel moisture and the equilibrium moisture content, and on timelag (Byram 1963 eqn. 1).

$$
F M C_{(t)}=\frac{F M C_{(t-1)}-\left(F M C_{(t-1)}-E M C\right)}{T L C}
$$

where $\mathrm{FMC}_{(\mathrm{t})}$ is the fuel moisture content at time $t(\%), E M C$ is the equilibrium moisture content (\%), TLC is the timelag constant (hour). EMC refers to the fuel moisture content finally attained under a constant temperature and relative humidity conditions, while TLC refers to the time for a particle of dead surface fuels to gain or lose approximately $2 / 3$ of the moisture contents between concurrent fuel moisture and EMC (Lopes et al. 2014a).

As can be derived from eqn. $1, F M C_{(t)}$ does not incorporate the effects of new rainfall nor condensation. The rain effect was incorporated into the model based on a sigmoid relationship developed using previous fuel moisture content, the amount of rain and saturation moisture content. The condensation effect was incorporated using an inverse sigmoid relationship developed using vapor pressure deficit (VPD), assuming that at low values of VPD (i.e., at very high relative humidity and low temperature values) water condenses on fuel surfaces (Wallace \& Hobbs 2006).

A simplified model flow chart is shown in Fig. 1. Major components of the model include: (i) input and initialization; (ii) moisture content increase due to rain; (iii) condensation effect; (iv) equilibrium moisture content calculation (EMC); (v) timelag and fuel moisture calculations. Diurnal moisture dynamics are determined hourly in the order set out in Fig. 1. Calculated moisture contents at the end of each hour are taken as the starting conditions for the next hour. The model requires as input hourly air temperature, relative humidity, wind speed and rainfall. A complete list of the variables included in the model are given in Tab. 1. The model components are described in more detail hereafter. 


\section{Input and initialization}

The model requires values for litter and duff moisture to start simulation. Initial values can either be entered manually or calculated by running the model for three days to establish a reference moisture value, using respective weather data with an arbitrary initial moisture content value of thirty-five percent (i.e., moisture of saturation) set for litter and duff. The duration of the initialization phase was based on the literature and model results. It is suggested that one to three days of simulation would normally be enough for litter and duff fuels to reach the moisture content values expected under respective weather conditions (Rothermel et al. 1986, De Dios et al. 2015). Repeated model runs also confirmed that moisture content values expected under respective weather conditions are reached within 24 hours of simulation, regardless of the initial moisture content values. Once the final reference values are obtained, these values are accepted as the initial values for litter and duff for the next hour of the simulation.

\section{Fuel moisture increase due to rain $(\mathrm{FMI})$}

The amount of rain is important to consider when estimating dead fuel moisture content as it can raise surface dead fuels moisture content more rapidly than any other weather variable. Surface fine dead fuels, especially litter, react very rapidly to rain and reach the saturation point quickly (Viney 1991). Additional rain has little effect on surface fuels approaching the saturation point (Van Wagner 1987). Based on the information above, a new relationship was developed to calculate moisture content increase after a rain event. The relationship uses previous fuel moisture content, the amount of rain, the amount of rain required for saturation and saturation moisture content. The increase of fuel moisture due to rain $\left(\mathrm{FMI}_{\mathrm{r}}\right.$, \%) was calculated as (eqn. 2):

$$
F M I_{r}=\left[1-e^{\left(-a_{1} \frac{R+W C F}{R R F S}\right)}\right]^{a_{2}} \cdot(S M C-F M C)
$$

where $R$ is the amount of rain ( $\mathrm{mm}$ ), SMC is the saturation moisture content (\%), FMC is the fuel moisture content (\%), $a_{1}$ and $a_{2}$ are model parameters; WCF is the water content of fuels ( $\mathrm{kg} \mathrm{\textrm {m } ^ { - 2 }}, \mathrm{mm}$ equivalent), which was estimated as (eqn. 3):

$$
W C F=(F L \cdot F M C) / 100
$$

while RRFS is the rain amount required for saturation ( $\mathrm{mm}$ ), obtained as follows (eqn. 4):

$$
R R F S=\frac{b_{1} \cdot F L}{1+F L}
$$

where $\mathrm{FL}$ is the fuel load (litter or duff, kg $\mathrm{m}^{-2}$ ), and $b_{1}$ is the model parameter.

SMC is the maximum moisture content attainable for a given fuel layer (litter of

Tab. 1 - Definition of variables used in model specification.

\begin{tabular}{|lll|}
\hline Variable & Description & Unit \\
\hline CE & Condensation effect on surface fuels & $\mathrm{mm}$ \\
\hline EMC & Equilibrium moisture content & $\%$ \\
\hline FMI $_{r}$ & Fuel moisture increase due to rain & $\%$ \\
\hline FMI $_{c}$ & Fuel moisture increase due to condensation & $\%$ \\
\hline SMC & Saturation moisture content & $\%$ \\
\hline FMC & Fuel moisture content & $\%$ \\
\hline R & Rainfall & $\mathrm{mm}$ \\
\hline RRFS & Rain required for saturation & $\mathrm{mm}$ \\
\hline RH & Relative humidity & $\%$ \\
\hline$T$ & Air temperature & ${ }^{\circ} \mathrm{C}$ \\
\hline TLC & Timelag constant & $\mathrm{hour}$ \\
\hline W & Wind speed & $\mathrm{km} \mathrm{h}^{-1}$ \\
\hline VPD & Atmospheric vapor pressure deficit & $\mathrm{Pa}^{-2}$ \\
\hline FL & Fuel load & $\mathrm{kg} \mathrm{m}^{-2}$ \\
\hline
\end{tabular}

duff). RRFS refers to the amount of rain required for complete saturation of dry fuels. The first part of eqn. 2 within brackets represents the rate of moisture increase after a rain event. The rate of change of moisture content depends on the amount of rain, the amount of moisture (water) currently available in fuels and the rain required for saturation. The water content of fuels in addition to the amount of rain was incorporated into the model to introduce the effect of fuel load. The difference between the present fuel moisture content (FMC) and the saturation moisture content (SMC) is then multiplied by the rate of moisture content change to calculate the increase in fuel moisture content. The relationship in eqn. 2 provides that the effect of rainfall decreases with increasing the amount of rain and the initial moisture content as the fuel moisture content approaches the saturation point (Van Wagner 1987). This model form also helps ensure low rates of moisture increases in the surface fuels under tree canopies at low amounts of rain $(<0.5 \mathrm{~mm}$ - Van Wagner 1987), thus accounting for the rain intercepted by tree canopies. This is accomplished by the $a_{2}$ coefficient of eqn. 2, which can dynamically change according to varying conditions. Such dynamic approach has been chosen (instead of subtracting a fixed rain amount for interception) to reflect the actual amount of rain affecting surface fuels in the stands, which is inversely related to canopy closure (Xiao et al. 2000). As for the calculations for the rainfall effect, rainfall was assumed to have occurred at the beginning of the time period.

RRFS relationship and SMC values were determined in relation to average moisture content values obtained from wetting experiments (see below). SMC values were taken as 150 and 300\% for surface litter and duff, respectively. These values are comparable with those reported in the literature (Tanskanen et al. 2006, Lopes et al. 2014b).

\section{Condensation effect}

One of the main problems in fuel moisture modeling is the increase of fuel moisture content due to the water condensation on its surface. Condensation of water on surface fuels can be caused by both water deposition from the atmosphere by distillation and the upward water transport from the soil by turbulent diffusion (Monteith 1963). So far, little work has been carried out to account for the condensation effect (Viney 1991). Viney \& Hatton (1990) provided a physical model to quantify the effects of nocturnal condensation on the moisture content of leaf litter. However, their model is complex, requiring many parameters that are not practically measured in the field (Jose et al. 2013). In this study, a different model form was developed using atmospheric vapor pressure deficit (VPD) to quantify the effect of condensation on the moisture content of surface fuels. It was based on the assumption that condensation takes place at very low VPD values, corresponding to very high relative humidity (e.g., over 90\%) and relatively lower temperature conditions (Wallace \& Hobbs 2006 - eqn. 5):

$$
C E=c_{1} \cdot\left(1-\frac{V P D^{c_{3}}}{c_{2}^{c_{3}}+V P D^{c_{3}}}\right)
$$

where $C E$ is the condensation effect $(\mathrm{mm})$, $c_{1}, c_{2}$ and $c_{3}$ are model parameters to be estimated, and VPD is the atmospheric vapor pressure deficit $(\mathrm{Pa})$, calculated after Bonan (2008 - eqn. 6$)$ :

$$
V P D=100-\left[R H \cdot 610.7 \cdot 10^{(7.5 \cdot T)(273.3+T)}\right]
$$

where $\mathrm{T}$ is air temperature $\left({ }^{\circ} \mathrm{C}\right), \mathrm{RH}$ is the relative humidity (\%).

In eqn. 5, the maximum amount of condensed water on fuels is represented by $c_{1}$ (determined from calibration data) and is related to the surface area (i.e., fuel load Agam \& Berliner 2006). The rationale behind the inclusion of CE relationship in the 
model is the observed difference between the calculated EMC and the actual moisture content for fuels under very high (e.g., $>90 \%$ ) relative humidity and relatively low temperature (e.g., $\left.<15{ }^{\circ} \mathrm{C}\right)$. Theferore, the value of $c_{1}$ was determined based on the difference between the calculated EMC and the actual values of fuel moisture content. The CE relationship (eqn. 5) has an inverse sigmoid shape, and $c_{2}$ and $c_{3}$ coefficients define the shape of the curve. The values of $c_{2}$ and $c_{3}$ were determined by multiple nonlinear regression analyses using field measurements.

The increase of fuel moisture content due to condensation $\left(\mathrm{FMI}_{\mathrm{c}}\right.$, \%) was then calculated as (eqn. 7):

$$
F M I_{c}=\frac{C E}{F L} \cdot 100
$$

where FL is the fuel load (litter or duff - kg $\mathrm{m}^{-2}$ ).

Using the estimated moisture increase due to rain and condensation described above, fuel moisture content of litter and duff $\left(\mathrm{FMC}_{(\mathrm{t})}\right.$, \%) were estimated at the beginning of the hour as follows (eqn. 8):

$$
F M C_{(t)}=F M C_{(t-1)}+F M I_{r}+F M I_{c}
$$

\section{Equilibrium moisture content}

$E M C$ is an intermediate variable used to predict fuel moisture contents finally attained by the fuels under constant air temperature and relative humidity (Blackmarr 1971). Several EMC models have been proposed (Simard 1968, Van Wagner 1972, Anderson et al. 1978, Nelson 1984, Catchpole et al. 2001) and used in fuel moisture prediction models (Van Wagner 1977, Matthews 2006, Slijepcevic et al. 2013, Lopes et al. 2014a, De Dios et al. 2015). To calculate the EMC of dead litter and duff of Calabrian pine stands, the Anderson et al. (1978)'s EMC formula for Pinus ponderosa needles, based on the desorption $\left(E M C_{d}\right)$ and adsorption $\left(E M C_{a}\right)$ models by Van Wagner (1972) were used (eqn. 9, eqn. 10):

$$
\begin{aligned}
E M C_{d} & =1.651 \cdot R H^{0.493} \\
& +0.001972 \cdot e^{0.092 R H} \\
& +0.101 \cdot(23.9-T) \\
E M C_{a} & =0.891 \cdot R H^{0.612} \\
& +0.000234 \cdot e^{0.092 R H} \\
& +0.101 \cdot(23.9-T)
\end{aligned}
$$

\section{Timelag}

Timelag is the time necessary for a fuel particle to gain or lose approximately $63.3 \%$ of the difference between its initial moisture content and its equilibrium moisture content (Byram 1963). Timelag is important for the moisture response characteristics of fine forest fuels. It is known that timelag can vary significantly in relation to concurrent weather conditions and stand and fuel bed characteristics such as crown closure, fuel bed thickness (Van Wagner 1979), fuel loading and density (Anderson et al. 1978). However, the variation between wetting and drying timelag periods is little and has no practical significance (Anderson et al. 1978). A new relationship which considers VPD and wind was developed to calculate timelag for litter and duff fuels. VPD is calculated from relative humidity and temperature and is a measure of the drying power of the air (Bonan 2008). The timelag constant (TLC, in hours) used in the model was then calculated as (eqn. 11);

$$
T L C=\left[d_{1} \cdot\left(1-\frac{V P D^{d_{3}}}{d_{2}^{d_{3}}+V P D_{3}^{d}}\right)+d_{4}\right] k_{w}
$$

where VPD is the vapor pressure deficit $(\mathrm{Pa}), d_{1}, d_{2}, d_{3}$ and $d_{4}$ are model parameters, which were determined by multiple nonlin- ear regression analyses using field measurements; the parameter $\mathrm{k}_{\mathrm{w}}$ in eqn, 11 represents a wind correction factor, which was calculated as follows (eqn. 12):

$$
k_{w}=1-\left(\frac{e_{1} \cdot W}{e_{2}+W}\right)
$$

where $\mathrm{W}$ is the wind speed $\left(\mathrm{km} \mathrm{h}^{-1}\right), e_{1}$ and $e_{2}$ are model parameters.

Although it may seem somewhat complex, the TLC relationship has a simple inverse sigmoid shape; $d_{1}$ and $d_{4}$ are the maximum and minimum timelag values, respectively, while $d_{2}$ and $d_{3}$ define the shape of the curve. The coefficients $d_{1}$ and $d_{4}$ were determined from validation data. Such relationship yields high values (slow drying) under high temperature and low relative humidity conditions. Moreover, the wind has a diminishing effect on TLC based on an inverse smoothing curve.

Timelag constant is then used along with EMC and initial moisture content of the fuels to calculate the final moisture content values at the end of the hour $\left(\mathrm{FMC}_{(\mathrm{t}+1)}, \%\right)$ for litter and duff (eqn. 13).

$F M C_{(t+1)}=\frac{F M C_{(t)}-\left(F M C_{(t)}-E M C\right)}{T L C}$

The estimated $F M C_{(t+1)}$ values then become the initial values for the next step of the simulation.

\section{Data collection}

\section{Study sites}

To determine the surface fuel moisture content changes under varying weather conditions, measurements were carried out in three geographic locations (Fig. 2) to reflect the widest range possible in weather parameters.

The first study area was in the Yaras State Forest in Mugla, south-western Turkey ( $37^{\circ}$

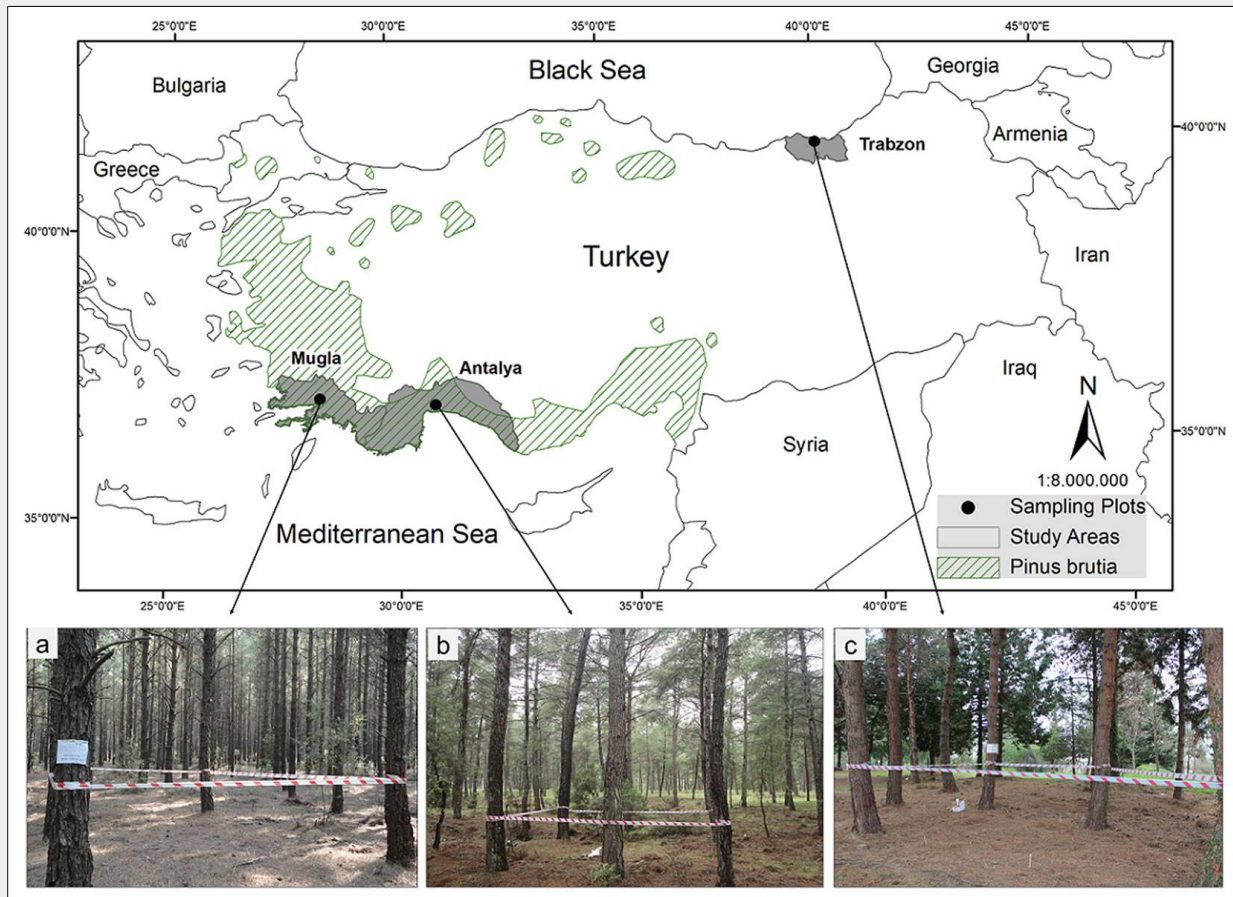

Fig. 2 - Geopraphic locations of study sites and sampling plots; Mugla (a), Antalya (b) and Trabzon (c). Dashed areas in the map shows the geographical distrubition of Calabrian pine in Turkey. 
$08^{\prime} \mathrm{N}, 28^{\circ} 30^{\prime} \mathrm{E}$; average elevation $750 \mathrm{~m}$ a.s.l.). The area has Mediterranean climate with prolonged dry summers and mild, moist winters. Average air temperature from May to October varies from 15 to 25 ${ }^{\circ} \mathrm{C}$, and the average monthly rainfall ranges from 7.8 to $68.3 \mathrm{~mm}$ for the same period. The fire season in Mugla region generally lasts from late May until mid-September.

The second study area is in Antalya, southern Turkey ( $37^{\circ} 08^{\prime} \mathrm{N}, 28^{\circ} 30^{\prime} \mathrm{E}$; average elevation $240 \mathrm{~m}$ a.s.l.). This area has climatic conditions similar to Mugla, characterized by prolonged dry summers and mild, moist winters. Average air temperature from May to October varies from 20 to $28{ }^{\circ} \mathrm{C}$, and the average monthly rainfall ranges from 3.1 to $80.1 \mathrm{~mm}$ for the same period. The fire season in the Antalya region generally lasts from late May until mid-September.

The third study area was in the Trabzon region, north-eastern Turkey $\left(40^{\circ} 59^{\prime} \mathrm{N}, 39^{\circ}\right.$ 46' E; av. elev. $50 \mathrm{~m}$ a.s.l.). The study area has a Black Sea climate characterized by warm and humid summers, long cool/cold and damp winters with high and evenly distributed rainfall the year round. Average air temperature from November to May varies from 7 to $16{ }^{\circ} \mathrm{C}$ and average monthly rainfall is between 58.5 to $96.1 \mathrm{~mm}$ for the same period. The fire season in Trabzon differs from other regions and generally lasts from November until early-May.

The study was conducted in pure, normally stocked ( $200-90 \%$ crown closure), and even-aged Calabrian pine stands. Sampling plots, $20 \times 20 \mathrm{~m}$ in size, were established in normally-stocked and nearly fullyclosed Calabrian pine stands in all three study areas. Plots were set up inside the stands at least $50 \mathrm{~m}$ away from open areas to avoid edge effect on fuel moisture. Measured stand characteristics included stand age, diameter at breast height (dbh), crown width, tree height, crown base height, canopy closure, stand density and basal area. Stand age was 41, 63 and 50 years; mean dbh 26.8, 37.1 and $34.2 \mathrm{~cm}$; mean crown width $4.6,8.3$ and $5.6 \mathrm{~m}$; mean tree height 14.0, 17.8 and $15.5 \mathrm{~m}$; mean crown base height 8.7, 10.2 and 8.9 $\mathrm{m}$; mean canopy closure 95, 80 and $85 \%$; mean stand density 725, 250 and 450 stem ha'; mean stand basal area 40.9, 27.0 and $41.3 \mathrm{~m}^{2}$ ha-1 for Mugla, Antalya and Trabzon, respectively.

No living plants were present in the understory within the stands, and living trees made up $100 \%$ of the overstory. Surface fuels consisted primarily of needle litter along with some branch and cone litter. Average litter and duff fuel loads in the measurement plots were $0.335,0.396$ and $0.405 \mathrm{~kg} \mathrm{~m}^{-2}$ and $1.647,1.005$ and $1.853 \mathrm{~kg}$ $\mathrm{m}^{-2}$ at Mugla, Antalya and Trabzon sites, respectively. Stand and surface fuel characteristics are given in Tab. 2.

\section{Weather measurements}

A fully automated weather station (Davis
Tab. 2 - Mean structural and surface fuel characteristics at the study plots.

\begin{tabular}{|c|c|c|c|c|c|c|}
\hline Feature & \multicolumn{2}{|c|}{ Variable } & Units & Mugla & Antalya & Trabzon \\
\hline \multirow[t]{10}{*}{ Stand } & \multicolumn{2}{|c|}{ Stand Origin } & - & Plantation & Natural & Plantation \\
\hline & \multicolumn{2}{|c|}{ Stand Age } & Year & 41 & 63 & 50 \\
\hline & \multicolumn{2}{|c|}{ Number of Plots } & $\#$ & 3 & 3 & 2 \\
\hline & \multicolumn{2}{|c|}{$\operatorname{DBH}\left(\mathrm{d}_{1.30}\right)$} & $\mathrm{cm}$ & 26.8 & 37.1 & 34.2 \\
\hline & \multicolumn{2}{|c|}{ Crown Width } & $\mathrm{m}$ & 4.6 & 8.3 & 5.6 \\
\hline & \multicolumn{2}{|c|}{ Tree Height } & $\mathrm{m}$ & 14.0 & 17.8 & 15.5 \\
\hline & \multicolumn{2}{|c|}{ Crown Base Height } & $\mathrm{m}$ & 8.7 & 10.2 & 8.9 \\
\hline & \multicolumn{2}{|c|}{ Canopy Closure } & $\%$ & 95 & 80 & 85 \\
\hline & \multicolumn{2}{|c|}{ Stand Density } & Stem ha ${ }^{-1}$ & 725 & 250 & 450 \\
\hline & \multicolumn{2}{|c|}{ Stand Basal Area } & $m^{2} h^{-1}$ & 40.9 & 27.0 & 41.3 \\
\hline \multirow{6}{*}{$\begin{array}{l}\text { Surface } \\
\text { Fuel }\end{array}$} & \multirow[t]{3}{*}{ Litter } & Fuel Depth & $\mathrm{cm}$ & 1.8 & 2.1 & 2.5 \\
\hline & & Fuel Load & $\mathrm{kg} \mathrm{m}^{-2}$ & 0.335 & 0.396 & 0.405 \\
\hline & & Fuel Density & $\mathrm{g} \mathrm{cm}^{-3}$ & 0.019 & 0.020 & 0.016 \\
\hline & \multirow[t]{3}{*}{ Duff } & Fuel Depth & $\mathrm{cm}$ & 4.1 & 3.2 & 3.9 \\
\hline & & Fuel Load & $\mathrm{kg} \mathrm{m}^{-2}$ & 1.647 & 1.005 & 1.853 \\
\hline & & Fuel Density & $\mathrm{g} \mathrm{cm}^{-3}$ & 0.040 & 0.031 & 0.048 \\
\hline
\end{tabular}

Vantage Pro $^{\mathrm{TM}}$, Davis Instruments Corp., Fuel moisture measurements

Hayward, CA, USA) was set up at the study Surface fuel moisture measurements sites to record weather variables. Measure- were carried out in the sampling plots evments involved rainfall $(\mathrm{mm})$, air tempera- ery two hours between 09:00-19:00. Five ture $\left({ }^{\circ} \mathrm{C}\right)$, relative humidity $(\%)$, wind speed fuel samples were taken from each plot for $\left(\mathrm{km} \mathrm{h}^{-1}\right)$ and direction. Weather measure- each sampling time. Each sample was obments were recorded continuously during tained from a sub-plot measuring $15 \times 20$ the period of fuel measurements. Weather $\mathrm{cm}$. All fuels within the sub-sampling plot measurements (Tab. 3) and calculated VPD was removed and separated as surface litvalues are provided in Fig. 3. Study periods ter (L layer, newly fallen surface litter) and included: (i) Mugla (24 days), August 22-31, duff (F layer, decomposed and/or decom2013 (M1) and August 14-27, 2014 (M2); (ii) posing organic matter below L layer). Fuel Antalya (10 days), April 20-29, 2014; (iii) Tra- samples were sealed in plastic containers, bzon ( 83 days), February 18 - May 10, 2016. weighed with $0.01 \mathrm{~g}$ precision and taken to

Tab. 3 - Weather and fuel moisture variables for the study areas. (M1, M2, A, T): different study periods at the three sampling sites (see text); (a): wind speed was measured at $10 \mathrm{~m}$ standard height in the open ground (Lawson \& Armitage 2008); (b): wetting experiment in Trabzon, where values represent moisture contents after wetting; (SD): standard deviation.

\begin{tabular}{|c|c|c|c|c|c|c|c|}
\hline \multirow{2}{*}{ Feature } & \multirow{2}{*}{ Variable } & \multirow{2}{*}{ Stats } & \multicolumn{2}{|c|}{ Mugla } & \multirow{2}{*}{$\begin{array}{c}\text { Antalya } \\
\text { A }\end{array}$} & \multirow{2}{*}{$\begin{array}{c}\text { Trabzon } \\
\mathrm{T}\end{array}$} & \multirow{2}{*}{$\begin{array}{c}\begin{array}{c}\text { Trabzon } \\
\text { WE }^{(b)}\end{array} \\
T\end{array}$} \\
\hline & & & M1 & M2 & & & \\
\hline \multirow[t]{10}{*}{ Weather } & \multirow{3}{*}{$\begin{array}{l}\text { Temperature } \\
\left({ }^{\circ} \mathrm{C}\right)\end{array}$} & Min & 17.1 & 19.9 & 8.6 & 2.4 & - \\
\hline & & Mean & 26.7 & 27.2 & 17.2 & 13.1 & - \\
\hline & & $\operatorname{Max}$ & 38.2 & 37 & 25.5 & 20.4 & - \\
\hline & \multirow{3}{*}{$\begin{array}{l}\text { Relative Humidity } \\
\text { (\%) }\end{array}$} & Min & 16 & 10 & 26 & 8 & - \\
\hline & & Mean & 35.4 & 44.5 & 73.4 & 72.4 & - \\
\hline & & Max & 71 & 69 & 95 & 96 & - \\
\hline & \multirow{3}{*}{$\begin{array}{l}\text { Wind Speed } \\
\left(\mathrm{km} \mathrm{h}^{-1}\right)\end{array}$} & Min & 0.2 & 0 & 0 & 0 & - \\
\hline & & Mean & 7.4 & 1.9 & 2.1 & 4.2 & - \\
\hline & & $\operatorname{Max}$ & 22.7 & 6.3 & 8 & 20.9 & - \\
\hline & Rainfall (mm) & Max & 0 & 0 & 1.2 & 2.8 & - \\
\hline \multirow{8}{*}{$\begin{array}{l}\text { Fuel } \\
\text { Moisture }\end{array}$} & \multirow{4}{*}{$\begin{array}{l}\text { Litter Moisture } \\
\text { (\%) }\end{array}$} & Min & 3.6 & 4.8 & 5.5 & 15.4 & 22.8 \\
\hline & & Mean & 8.8 & 8.4 & 17.9 & 24.7 & 72.7 \\
\hline & & Max & 17.2 & 11.6 & 51.8 & 50.7 & 160.2 \\
\hline & & SD & 2.9 & 1.4 & 17.8 & 9.3 & 21.9 \\
\hline & \multirow{4}{*}{$\begin{array}{l}\text { Duff Moisture } \\
\text { (\%) }\end{array}$} & Min & 6.3 & 5.7 & 9.1 & 44.2 & 71.2 \\
\hline & & Mean & 8.1 & 9.2 & 32.3 & 67.8 & 160.9 \\
\hline & & Max & 10.3 & 12.8 & 81.1 & 98.9 & 360.3 \\
\hline & & SD & 1 & 1.9 & 24.6 & 13 & 59.2 \\
\hline
\end{tabular}




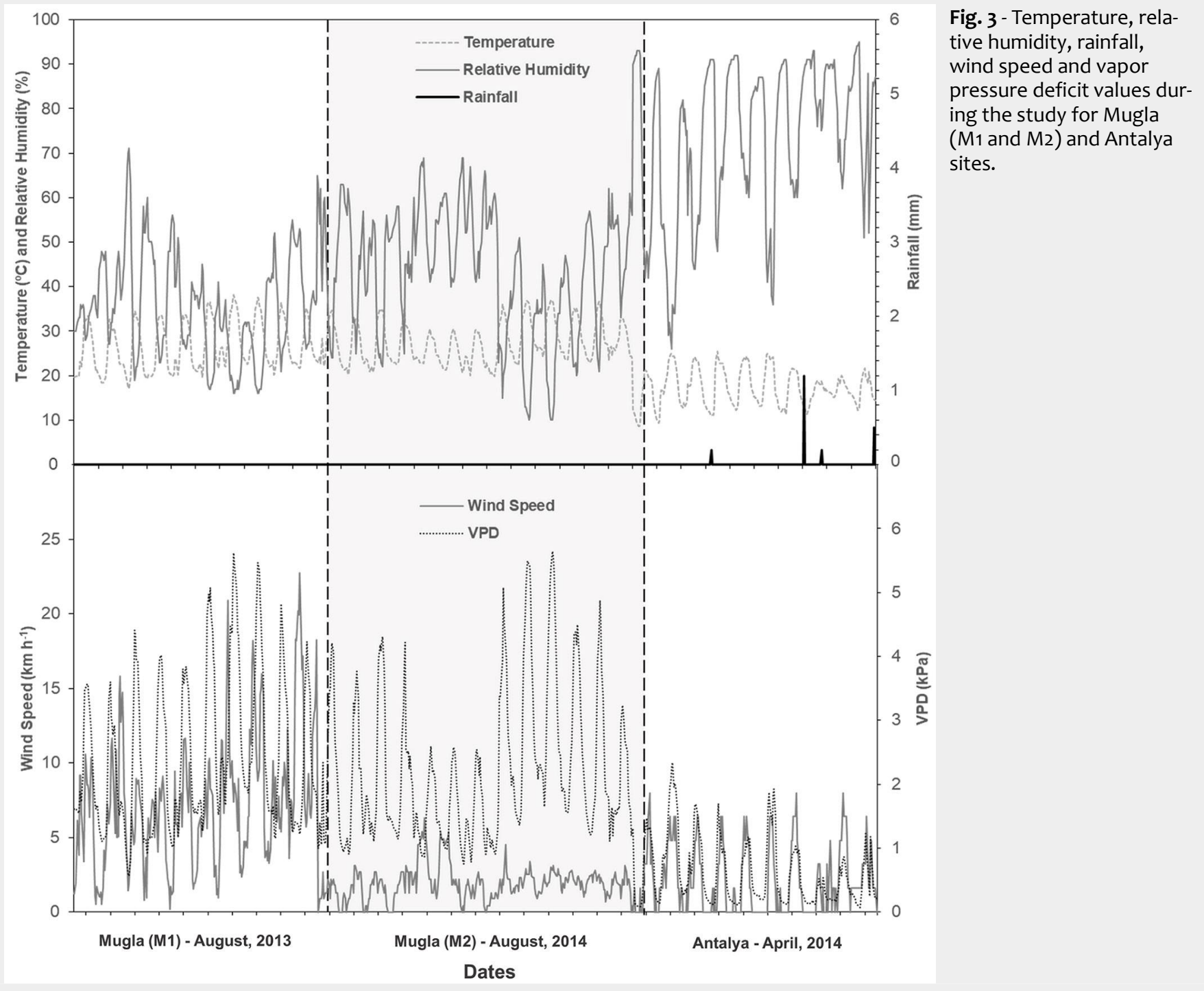

the laboratory. Measurements continued until the end of the study period. All litter and duff samples were oven-dried at $105^{\circ} \mathrm{C}$ for $24 \mathrm{~h}$ and weighed to obtain fuel moisture contents (Pook \& Gill 1993). Moisture content values were determined based on an oven-dry weight basis. The relationship between litter (LMC) and duff (DMC) moisture content and temperature and relative humidity are displayed in Fig. S1 (Supplementary material).

Some descriptive statistics of weather and fuel moisture are provided in Tab. 3.

\section{Measurements of fuel moisture increase due to rain}

To determine moisture content increase after a rain event, a wetting experiment was further conducted immediately before, during and after a rain event. To determine fuel moisture increase after wetting, fuel containers measuring $15 \times 20 \mathrm{~cm}$ in size were prepared for litter and duff using nets of $1 \times 1 \mathrm{~mm}$ mesh size. Containers were placed in plots measuring $1 \times 1 \mathrm{~m}$ with three replicates for litter and duff. To wet the samples, tap water was used in quantities of $0.2,0.5,1.0,2.0,5.0,7.0$ and 10.0 liters (rain equivalent of $0.2 \mathrm{~mm}$ to $10 \mathrm{~mm}$ ). Uniform artificial raindrops were produced over the $1 \times 1 \mathrm{~m}$ study plot by a water sprinkler (Sato et al. 2004). Litter and duff samples were weighed immediately before and after wetting. After measurements, litter and duff samples were taken to the laboratory and oven-dried, and moisture content values determined on an oven-dry weight basis. A total of 94 fuel moisture content values were determined for litter and duff. These records were used to determine the maximum potential moisture increase in fuels.

Furthermore, litter and duff samples were taken from the study plots in Trabzon before, during and immediately after a rain event. As a result, a total of 13 rain events over 8 different days were documented throughout the study period.

\section{Model parameterization}

Parameter values for fuel moisture increase due to rain, condensation, timelag constant, wind effect on timelag were obtained by fitting the model by non-linear least squares regression (SPSS Inc. 2013) and calibrated using the test data sets from Mugla (M1) and Trabzon (Tab. 4). Results were evaluated statistically, and the model results (graphs) were compared with the calibration data visually. The parameter values yielding the best approximation of the observed values were accepted as the model parameters. The parameter values used in the simulations are given in Tab. 4.

After calibration, the model was further tested against the independent data sets from Mugla (M2) and Antalya study sites for validation.

\section{Model validation and performance}

To assess the accuracy of model predictions (Huang et al. 2003), an independent data set from Mugla (M2) and Antalya study areas was used. Model parameters were not adjusted for the validation runs. Model validation was assessed using both graphical and statistical methods (Cook 1994, Huang et al. 2003). Three statistical criteria obtained from the residuals were examined to test the accuracy and precision of the predicted moisture content: mean absolute error (MAE), mean absolute percentage error (MAPE) and adjusted co- 
efficient of determination $\left(R_{\text {adj }}^{2}\right)$ of the regression of predicted vs. observed values (Gonzalez et al. 2009).

All statistical analyses were conducted using the software package SPSS ${ }^{\circledR}$ ver. 22.0 (SPSS Inc. 2013).

\section{Results}

Data used for calibration and validation of the model covered a significant range of weather conditions (Tab. 3). Temperature, relative humidity, wind speed and rainfall ranged from 2.4 to $38.2{ }^{\circ} \mathrm{C}, 8$ to $96 \%, 0.0$ to $22.7 \mathrm{~km} \mathrm{~h}^{-1}$ and 0.0 to $2.8 \mathrm{~mm}$, respectively. The time series of the observed fuel moisture contents plotted together with the predicted values from the model are shown in Fig. 4 for Mugla (Fig. 4a, Fig. 4b) and Antalya (Fig. 4C, Fig. 4d) sites.

The relationships between measured and predicted litter and duff moisture contents for Mugla and Antalya sites are given in Fig. 5.

The visual and statistical evaluation of the results indicated that the accuracy of model predictions for both litter and duff moisture was satisfactory for Mugla and Antalya sites. However, we observed some discrepancies between the observed and predicted values of duff at the Antalya site, where the model systematically underestimated duff moisture contents during the period April 20-23 and April 28-29 (Fig. 4d, Fig. $5 \mathrm{~d}$ ). A revisit of the data indicated that while there was no precipitation recorded by the weather station during these periods, ground fuels and soil were somewhat saturated by occasional rain on the days preceding and continuous drizzle accompanied by high relative humidity on parts of these days.

The validation statistics of the comparison between predicted and observed fuel moisture content values for the two sites are given in Tab. 5. Observed fuel moisture contents in the validation data sets ranged from 4.83 to $11.59 \%$ for litter and 5.66 to $12.84 \%$ for duff at Mugla site, and from 5.48 to $51.81 \%$ for litter and 9.07 to $81.06 \%$ for duff at Antalya site. Model predictions yielded a MAE of 1.19 for litter and $0.90 \%$ for duff at Mugla and $3.62 \%$ for litter and $14.38 \%$ for duff at Antalya. When the periods of April 20-23, 2014 and April 28-29, 2014 were excluded from the validation data at Antalya site, the MAE decreased from 14.38 to 4.29 and $R^{2}$ increased from 0.25 to 0.83 for duff fuels with the corresponding standard errors (SE) from 15.06 to 4.93 (Tab. 5). The validation statistics (MAE, MAPE and $R^{2}$ ) of model predictions on validation data from Mugla (M2) and Antalya (Tab. 5) also supported the conclusion reached by the visual evaluation.

As for the rainfall effect, despite there were only three rainfall occurrences with limited amount of precipitation, the response and performance of the model in case of a rain event was also satisfactory (Fig. 4C, Fig. 4d).
Tab. 4 - Parameter values used in the model.

\begin{tabular}{|c|c|c|c|}
\hline \multirow{2}{*}{ Variable } & \multirow{2}{*}{$\begin{array}{c}\text { Model } \\
\text { Parameter }\end{array}$} & \multicolumn{2}{|c|}{ Value } \\
\hline & & Litter & Duff \\
\hline \multirow{2}{*}{ Fuel moisture increase due to rain $\left(\mathrm{FMI}_{\mathrm{r}}\right), \%$} & $a_{1}$ & 25 & 30 \\
\hline & $a_{2}$ & 2.8 & 3.5 \\
\hline \multirow{2}{*}{ Rain required for saturation (RRFS), $\mathrm{mm}$} & $b_{1}$ & 50 & 40 \\
\hline & $b_{2}$ & 1 & 1 \\
\hline \multirow{3}{*}{ Condensation effect (CE), mm } & $c_{1}$ & 0.07 & 0.25 \\
\hline & $c_{2}$ & 15 & 20 \\
\hline & $c_{3}$ & 1.4 & 2 \\
\hline \multirow{4}{*}{ Timelag (TLC), hour } & $d_{1}$ & 50 & 75 \\
\hline & $d_{2}$ & 50 & 75 \\
\hline & $d_{3}$ & 3 & 4 \\
\hline & $d_{4}$ & 3 & 3 \\
\hline \multirow{2}{*}{ Wind effect on TLC $\left(k_{w}\right), \mathrm{km} \mathrm{h}^{-1}$} & $e_{1}$ & 0.3 & 0.1 \\
\hline & $e_{2}$ & 10 & 10 \\
\hline
\end{tabular}

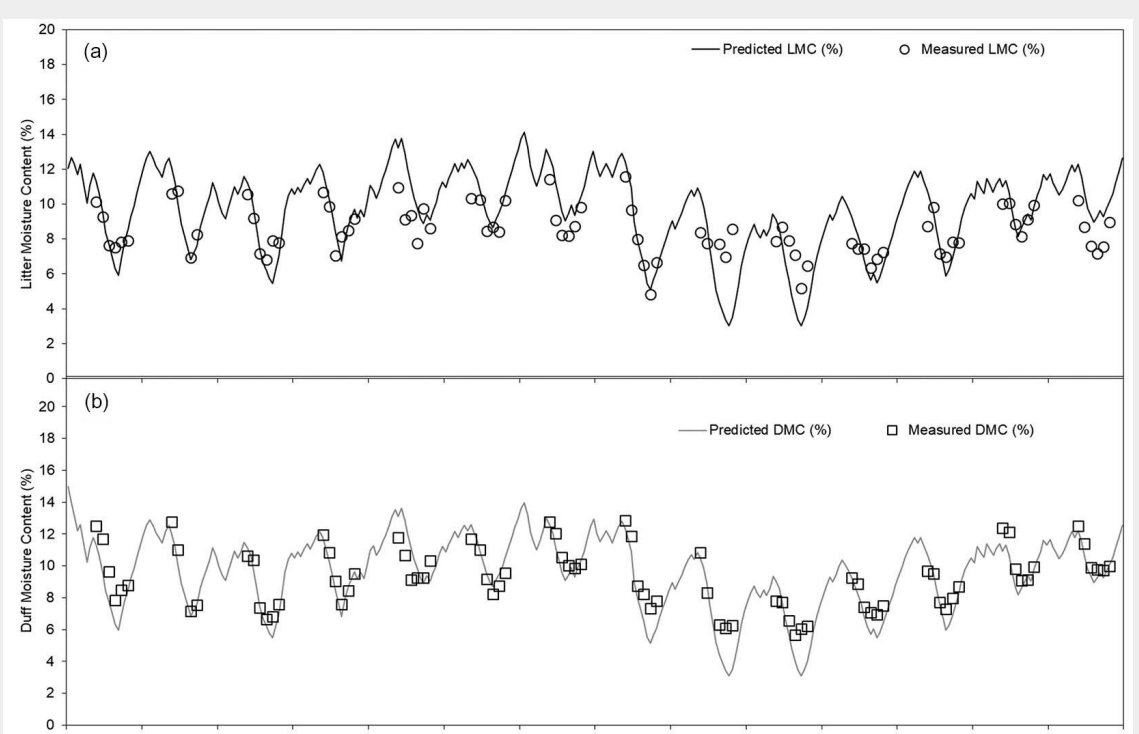

14 August 15 August 16 August 17 August 18 August 19 August 20 August 21 August 22 August 23 August 24 August 25 August 26 August 27 August
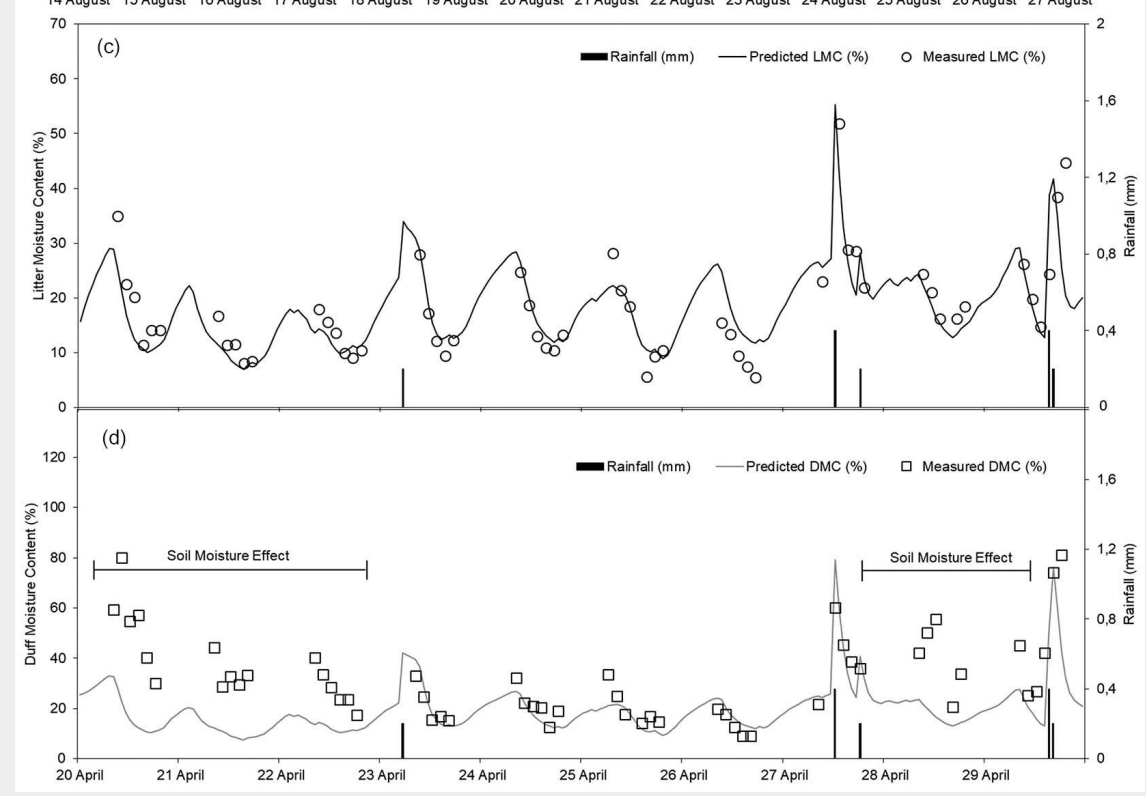

Fig. 4 - Time series of hourly predicted and observed litter (a, c) and duff (b, d) mois ture contents for the period of August 14-27, 2014 in Mugla (a, b) and April 20-29, 2014 in Antalya (c, d), respectively. 

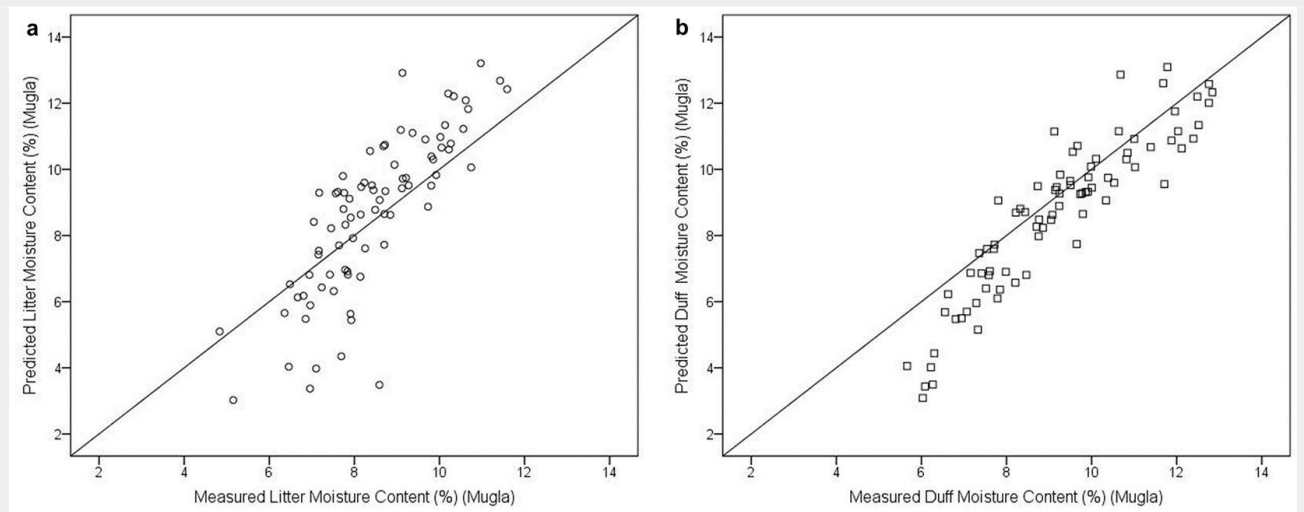

Fig. 5 - The relationships between measured and predicted litter (a, c) and duff (b, d) moisture contens for Mugla and Antalya.
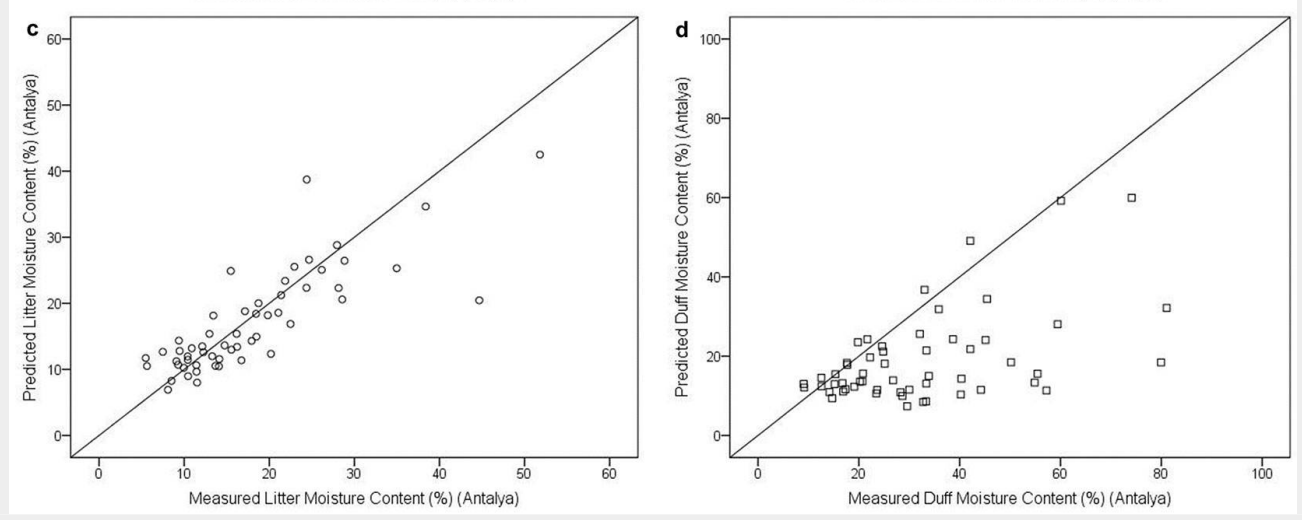

\section{Discussion}

The proposed model produced reasonable fits to the validation data. As expected, the accuracy of model predictions was higher during dry periods when moisture content is low, though litter moisture dynamics were predicted reasonably well under all weather conditions (Fig. 4a, Fig. 4c). However, there was a systematic underestimation of duff moisture contents at Antalya site during the period of April 20-23 and April 28-29, 2014 (Fig. 4d, Fig. 5d). These periods coincided with days immediately after rain events.

The accuracy of model predictions in Mugla was similar to other studies (Pook 1993, Gonzalez et al. 2009). However, the accuracy of model predictions in Antalya was comparatively lower. This can be attributed to:

(i) the range of the moisture content predictions: the range of LMC was 5.48-51.81\% and that of DMC $9.07-81.06 \%$ for the Antalya site, covering rainy and dry periods

Tab. 5 - Statistics of the comparison between observed litter (LMC) and duff (DMC) moisture content values with validation data. (MAE): mean absolute error; (MAPE): mean absolute percentage error; $\left(R_{\text {adj }}^{2}\right)$ : adjusted coefficient of determination; (SE): standard error. (*): DMC values were excluded from the validation data set at Antalya during the periods April, 20-23 and April, 28-29 when soil moisture was high.

\begin{tabular}{|c|c|c|c|c|c|c|c|c|c|c|}
\hline \multirow{2}{*}{ Area } & \multicolumn{2}{|c|}{$\begin{array}{c}\text { Number of } \\
\text { measures }\end{array}$} & \multicolumn{2}{|c|}{ MAE } & \multicolumn{2}{|c|}{ MAPE } & \multicolumn{2}{|c|}{$\mathbf{R}_{\text {adj }}^{2}$} & \multicolumn{2}{|c|}{ SE } \\
\hline & LMC & DMC & LMC & DMC & LMC & DMC & LMC & DMC & LMC & DMC \\
\hline $\begin{array}{l}\text { Mugla } \\
\text { (M2) }\end{array}$ & 81 & 81 & 1.19 & 0.90 & 14.68 & 10.83 & 0.66 & 0.84 & 0.80 & 0.76 \\
\hline Antalya & 55 & 55 & 3.62 & 14.38 & 22.19 & 38.73 & 0.67 & 0.25 & 5.41 & 15.06 \\
\hline Antalya* & - & 27 & - & 4.29 & - & 19.55 & - & 0.83 & - & 4.93 \\
\hline
\end{tabular}

(Fig. 4C, Fig. 4d). The results of the study are consistent with many previous studies attributing reduced performance of models at higher moisture contents to greater variability in moisture contents of wet fuels (Catchpole et al. 2001, Matthews et al. 2007, Nolan et al. 2016).

(ii) Slight differences in stand structure and surface fuel characteristics (Tab. 2): it is known that stand structure and fuel bed properties might produce significant variations in the moisture content of fuels (Blackmarr 1971). Although the study sites in Mugla and Antalya were similar, stand density and canopy closure were relatively lower, and surface fuels were more heterogeneous at Antalya site. While the purpose of the model is to simulate fuel moisture content within fully grown and normally stocked tree stands, the effect of variable stand structure on the actual amount of water reaching the surface fuels under canopy becomes more pronounced, especially after rain events. In this study, the re- lationships concerning fuel moisture increases due to rain has been established using a limited precipitation dataset measured outside the stand. Therefore, further studies should involve two simultaneous measurements of fuel moisture contents (one under the canopy and one in the open) to establish a relationship between the precipitation measured outside the stand and the actual moisture content increase under tree canopies. The relationship thus developed may be substituted to the $a_{2}$ coefficient of eqn. 2 .

(iii) Potential soil moisture effect not accounted for: the effect of soil moisture on the moisture content of surface fuels has been clearly demonstrated (Rothermel et al. 1986, Matthews 2014). The initial underestimation of duff moisture contents on April, 20-23 and later on April, 28-29 at Antalya site can thus be ascribed to the presence of relatively high soil moisture (Fig. $4 d$, Fig. 5d) resulted from rain events preceding these periods, and affecting the dynamics of water exchanges through the fuel layers (Pook \& Gill 1993, Schaap et al. 1997). This may also partly explain the comparatively lower model performance for the litter fuels during these periods (Fig. 4c). The model presented here was not constructed to include the effect of soil moisture on the moisture dynamics of surface fuels. During the dry periods, the mineral soil had minimal influence on the drying processes of the duff (Keith et al. 2010, Johnson et al. 2013) and litter. Although not substantiated, the effect of lengthy drizzles and fog may also contribute to and have a pronounced effect on the dynamics of water exchanges through the fuel lay- 
ers. However, the model presented here does not account for either drizzle or fog. Given the limitations of the present study, it is highly suggested that future models consider the contribution of soil moisture to surface fuel moisture dynamics especially during damp periods, lengthy drizzles and fog. In this regard, existing models taking soil moisture into account (Wittich 2005) may be consulted.

\section{Conclusions}

In this study, an attempt was made to predict diurnal surface fuel moisture dynamics in Calabrian pine stands in Turkey by developing a deterministic dynamic model assembled from empirical relationships over a wide range of weather situations. Model inputs were hourly air temperature, relative humidity, wind speed and the amount of rain readily measured in the field. The performance of the model under varying weather conditions and different stand characteristics was reasonably accurate for dry periods or periods with occasional rain events. Lower performances of the model at the Antalya site was probably caused by the presence of high soil moisture affecting surface fuel during the first three days of observation.

The proposed model has been developed for fire danger rating predictions in fully grown (tree height: 15-20 m), normally stocked (basal area: $30-50 \mathrm{~m}^{2}$ ha $^{-1}$; crown closure: $80-100 \%$ ) pine stands. Its application to other Mediterranean stand types should be performed with caution, and only when specific model parameters (e.g., timelag, condensation and wind effect) are available.

More experimental research on the effects of soil moisture on surface fuel moisture content dynamics are needed for future model development. Moreover, future efforts should further improve model accuracy by testing the model over a wider range of stand characteristics and conditions.

\section{Acknowledgements}

We would like to extend our appreciation and thanks to Mugla and Antalya Regional Forest Directorate and its staff. This study was supported by The Scientific and Technological Research Council of Turkey, project no. TOVAG-1120809. We are grateful to two anonymous reviewers for their useful suggestions and comments that greatly improved the manuscript.

\section{References}

Agam N, Berliner PR (2006). Dew formation and water vapor adsorption in semi-arid environments. A review. Journal of Arid Environments. 65. 4: 572-590. - doi: 10.1016/j.jaridenv.2005.09. 004

Anderson HE, Schuetta RD, Mutch RW (1978). Timelag and equililbrium moisture content of ponderosa pine needles. Research Paper INT202, USDA Forest Service, Ogden, Utah, USA, pp. 1-29.
Bilgili E, Coskuner KA, Usta Y, Goltas M (2018). Modeling surface fuels moisture content in Pinus brutia stands. Journal of Forestry Research 30 (2): 577-587. - doi: 10.1007/s11676-018-0702-x Blackmarr WH (1971). Equilibrium moisture content of common fine fuels found in southeastern forests. Research Paper SE-74, USDA Forest Service, Asheville, NC, USA, pp. 1-8.

Bonan G (2008). Ecological climatology. Cambridge University Press, Cambridge, UK, pp. 201.

Byram GM (1963). An analysis of the drying process in forest fuel material. In: Proceedings of the International Symposium "Humidity and Moisture". Washington (DC, USA) 20-23 May 1963, pp. 1-38.

Catchpole EA, Catchpole WR, Viney NR, McCaw WL, Marsden-Smedley JB (2001). Estimating fuel response time and predicting fuel moisture content from field data. International Journal of Wildland Fire 10 (2): 215-222. - doi: 10.1071/WF 01011

Cook RD (1994). An introduction to regression graphics. John Wiley and Sons, New York, USA, pp. 253.

De Dios VR, Fellows AW, Nolan RH, Boer MM, Bradstock RA, Domingo F, Goulden ML (2015). A semi-mechanistic model for predicting the moisture content of fine litter. Agricultural and Forest Meteorology 203:64-73. - doi: 10.1016/j. agrformet.2015.01.002

GDF (2015). Forests and forestry in Turkey. General Directorate of Forestry, Ministry of Forestry, Ankara, Turkey, pp. 12.

Gonzalez ADR, Hidalgo JAV, Gonzalez JGA (2009). Construction of empirical models for predicting Pinus sp. dead fine fuel moisture in NW Spain. I: Response to changes in temperature and relative humidity. International Journal of Wildland Fire 18 (1): 71-83. - doi: 10.1071/ WF07101

Huang S, Yang Y, Wang Y (2003). A critical look at procedures for validating growth and yield models. In: "Modelling Forest Systems" (Amaro A, Reed D, Soares $P$ ). Wallingford, UK, pp. 271-293.

Johnson EA, Keith DM, Martin YE (2013). Comparing measured duff moisture with a water budget model and the duff and drought codes of the Canadian Fire Weather Index. Forest Science 59 (1): 78-92. - doi: 10.5849/forsci.11-037 Jose RS, Perez JL, Gonzalez RM, Pecci J, Palacios $M$ (2013). Sensitivity analysis of fire behaviour simulations over Spain Wth Wrf-fire. In: Proceedings of the International Conference "Harmonisation within Atmospheric Dispersion Modelling for Regulatory Purposes". Madrid (Spain) 6-9 May 2013, pp. 138-143. - doi: 10.1504/ IJEP.2014.065919

Keith DM, Johnson EA, Valeo C (2010). Moisture cycles of the forest floor organic layer $(\mathrm{F}$ and $\mathrm{H}$ layers) during drying. Water Resources Research. 46: 7. - doi: 10.1029/2009WRoo7984

Lawson BD, Armitage OB (2008). Weather guide for the Canadian forest fire danger rating system. Canadian Forestry Service Northern Forestry Center, Edmonton, Alberta, Canada, pp. 73.

Lopes S, Viegas DX, De Lemos LT, Viegas MT (2014a). Equilibrium moisture content and timelag of dead Pinus pinaster needles. Interna- tional Journal of Wildland Fire 23 (5): 721-732. doi: 10.1071/WF13084

Lopes S, Viegas DX, Lemos LD, Viegas MT (2014b). Rainfall effects on fine forest fuels moisture content. In: "Advances in Forest Fire Research" (Viegas DX eds). Imprensa da Universidade de Coimbra, Portugal, pp. 1256-1263. Matthews S (2006). A process-based model of fine fuel moisture. International Journal of Wildland Fire 15 (2): 155-168. - doi: 10.1071/WFo 5063

Matthews S, McCaw WL, Neal JE, Smith RH (2007). Testing a process-based fine fuel moisture model in two forest types. Canadian Journal of Forest Research 37 (1): 23-35. - doi: 10.113 9/x06-207

Matthews S (2014). Dead fuel moisture research: 1991-2012. International Journal of Wildland Fire 23 (1): 78-92. - doi: 10.1071/WF13005

Monteith JL (1963). Gas exchange in plant communities. In: "Environmental Control of Plant Growth” (Evans LT ed). Academic Press, New York, USA, pp. 95-112.

Nelson RM (1984). A method for describing equilibrium moisture-content of forest fuels. Canadian Journal of Forest Research 14 (4): 597-600. - doi: 10.1139/x84-108

Nelson RM (2000). Prediction of diurnal change in 10-h fuel stick moisture content. Canadian Journal of Forest Research 30 (7): 1071-1087. doi: 10.1139/x00-032

Nelson RM (2001). Water relations of forest fuels. In: "Forest Fires: Behaviour and Ecological Effects" (Johnson EA, Miyanishi K eds). Academic Press, San Diego, USA, pp. 79-149.

Nolan RH, De Dios VR, Boer MM, Caccamo G, Goulden ML, Bradstock RA (2016). Predicting dead fine fuel moisture at regional scales using vapour pressure deficit from MODIS and gridded weather data. Remote Sensing of Environment 174: 100-108. - doi: 10.1016/j.rse.2015.12.010 Pook EW, Gill AM (1993). Variation of live and dead fine fuel moisture in Pinus radiata plantations of the Australian-Capital-Territory. International Journal of Wildland Fire 3 (3): 155-168. doi: 10.1071/WF9930155

Pook EW (1993). Empirical models evaluated for prediction of fine fuel moisture in Australian $\mathrm{Pi}$ nus radiata plantations. New Zealand Journal of Forestry Science 23 (3): 278-297. [online] URL: http://www.scionresearch.com/_data/assets/p df file/0019/17704/NZJFS2331993POOK278_297 .pdf

Rothermel RC, Wilson RA, Morris GA, Sackett SS (1986). Modeling moisture content of fine dead wildland fuels - input to the behave fire prediction system. Research Paper 359, Intermountain Research Station, USDA Forest Service, Ogden, Utah, USA, pp. 1-61.

Saglam B, Bilgili E, Kucuk O, Dincdurmaz B (2006). Determination of surface fuels moisture contents based on weather conditions. Forest Ecology and Management. 1: 234. - doi: 10.1016/j.foreco.2006.08.107

Sato Y, Kumagai T, Kume A, Otsuki K, Ogawa S (2004). Experimental analysis of moisture dynamics of litter layers - the effects of rainfall conditions and leaf shapes. Hydrological Processes 18 (16): 3007-3018. - doi: 10.1002/hyp.57 46

Schaap MG, Bouten W, Verstraten JM (1997). 
Forest floor water content dynamics in a Douglas fir stand. Journal of Hydrology. 201 (1-4): 367-383. - doi: 10.1016/S0022-1694(97)00047-4 Schroeder M, Buck C (1970). Fire weather: a guide for application of meteorological information to forest fire control operations. Agriculture Handbook 360, USDA Forest Service, Intermountain Research Station, Ogden, UT, USA, pp. 360. [online] URL: http://digitalcom mons.usu.edu/cgi/viewcontent.cgi?article $=1013$ \&context=barkbeetles

Schunk C, Leutner C, Leuchner M, Wastl C, Menzel A (2013). Equilibrium moisture content of dead fine fuels of selected central European tree species. International Journal of Wildland Fire 22 (6): 797-809. - doi: 10.1071/WF12105 Sievanen R, Burk TE, Ek AR (1988). Construction of a stand growth-model utilizing photosynthesis and respiration relationships in individual trees. Canadian Journal of Forest Research 18 (8): 1027-1035. - doi: 10.1139/x88-156

Simard AJ (1968). The moisture content of forest fuels - I. A review of basic concepts. Report no. FF-X-14, Canadian Department of Forest and Rural Development, Forest Fire Research Institute, Ottawa, Ontario, Canada, pp. 47.

Slijepcevic A, Anderson WR, Matthews S (2013). Testing existing models for predicting hourly variation in fine fuel moisture in eucalypt forests. Forest Ecology and Management 306: 202-215. - doi: 10.1016/j.foreco.2013.06.033
SPSS Inc. (2013). IBM SPSS Statistics for Windows, ver 22.0. IBM Corp., Armonk, NY, USA.

Tanskanen H, Granstrom A, Venalainen A, Puttonen $P$ (2006). Moisture dynamics of moss-dominated surface fuel in relation to the structure of Picea abies and Pinus sylvestris stands. Forest Ecology and Management. 2261 (3): 189-198. doi: 10.1016/j.foreco.2006.01.048

Tavsanoglu C, Gürkan B (2009). Post-fire regeneration of a Pinus brutia (Pinaceae) forest in Marmaris National Park, Turkey. International Journal of Botany 5 (1): 107-111. - doi: 10.3923/ ijb.2009.107.111

Turna I, Bilgili E (2006). Effect of heat on seed germination of Pinus sylvestris and Pinus nigra ssp. pallasiana. International Journal of Wildland Fire 15 (2): 283-286. - doi: 10.1071/WF05069 Van Wagner CE (1972). Equilibrium moisture contents of some fine forest fuels in eastern Canada. Petawawa Forest Experimental Station, Chalk River, Ontario, Canada, pp. 11.

Van Wagner CE (1977). A method of computing fine fuel moisture content throughout the diurnal cycle. Information Report PS-X-69, Canadian Forest Service, Chalk River, Ontario, Canada, pp. 15.

Van Wagner CE (1979). A laboratory study of weather effects on the drying rate of jack pine litter. Canadian Journal of Forest Research 9 (2): 267-275. - doi: 10.1139/x79-044

Van Wagner CE (1987). Development and struc- ture of the Canadian forest fire weather index system. Technical Report PS-X-35, Ottawa, Ontario, Canada, pp. 37.

Viney NR, Hatton TJ (1990). Modelling the effect of condensation on the moisture content of forest litter. Agricultural and Forest Meteorology 51 (1): 51-62. - doi: 10.1016/0168-1923(90)900 41-4

Viney NR (1991). A review of fine fuel moisture modelling. International Journal of Wildland Fire 1 (4): 215-234. - doi: 10.1071/WF9910215

Wallace JM, Hobbs PV (2006). Atmospheric science: an introductory survey. Academic Press, San Diego, CA, USA, pp. 504.

Wittich KP (2005). A single-layer litter-moisture model for estimating forest-fire danger. Meteorologische Zeitschrift 14 (2): 157-164. - doi: 10.112 7/0941-2948/2005/0017

Xiao QF, McPherson EG, Ustin SL, Grismer ME (2000). A new approach to modeling tree rainfall interception. Journal of Geophysical Research - Atmospheres 105 (D23): 29173-29188. doi: 10.1029/2000JD900343

\section{Supplementary Material}

Fig. S1 - The relationship between fuel moisture contents and temperature and relative humidity.

Link: Bilgili_2870@supplo01.pdf 